Molecules 2007, 12, 2327-2340

\title{
molecules
}

ISSN 1420-3049

(C) 2007 by MDPI

www.mdpi.org/molecules

Full Paper

\section{Electrochemical Behavior and Antioxidant and Prooxidant Activity of Natural Phenolics}

\author{
Aleksandra Simić, Dragan Manojlović *, Dejan Šegan and Marija Todorović \\ Faculty of Chemistry, University of Belgrade, Studentski trg 12-16, 11000 Belgrade, Serbia; \\ E-mails: simic@chem.bg.ac.yu, segand@chem.bg.ac.yu, marijat@chem.bg.ac.yu \\ * Author to whom correspondence should be addressed; E-mail: manojlo@chem.bg.ac.yu
}

Received: 15 June 2007; in revised form: 4 October 2007 / Accepted: 4 October 2007 / Published: 24 October 2007

\begin{abstract}
We have investigated the electrochemical oxidation of a number natural phenolics (salicylic acid, $m$-hydroxybenzoic acid, $p$-hydroxybenzoic acid, protocatechuic acid, $o$-coumaric acid, $m$-coumaric acid, $p$-coumaric acid, caffeic acid, quercetin and rutin) using cyclic voltammetry. The antioxidant properties of these compounds were also studied. A structural analysis of the tested phenolics suggests that multiple $\mathrm{OH}$ substitution and conjugation are important determinants of the free radical scavenging activity and electrochemical behavior. Compounds with low oxidation potentials (Epa lower than 0.45) showed antioxidant activity, whereas compounds with high Epa values (>0.45) act as prooxidants.
\end{abstract}

Keywords: Phenolics; cyclic voltammetry; antioxidant activity; prooxidant activity

\section{Introduction}

Phenolic compounds are a complex group of substances that have attracted considerable attention due to their roles in providing flavor and color characteristics of food and in human health [1-3]. Many of the benefits associated with consumption of phenolic-rich foods are associated with their antioxidant activities [4, 5]. It is reported that phenolics may prevent lipid peroxidation via hydrogen atom donation from the hydroxyl group(s) attached to the benzene ring [5]. However, the connection between the structure of phenolics and their antioxidant activity are still being actively investigated. 
Measurements of the reducing capacity and electrochemical behavior of phenolic compounds may provide useful information about the free radical scavenging activity of natural occurring phenols. The purpose of this study was to undertake such an investigation and to compare the redox potentials with data obtained from lipid peroxidation assays.

\section{Results and Discussion}

The main characteristic of all phenols is that they contain one or more hydroxyl groups attached to benzene ring. Structurally phenols may be divided into two mayor classes: phenolic acids (essentially hydroxybenzoic and hydroxycinnamic acid) and flavonoids. We have analyzed a range of different phenolics, whose structures are shown in Figure 1.

Figure 1. Structures of the tested phenolic compounds.

Benzoic acid derivatives<smiles>O=C(O)c1ccccc1O</smiles><smiles>O=C(O)c1cccc(O)c1</smiles>

salicylic acid<smiles>O=C(O)c1ccc(O)cc1</smiles>

p-hydroxybenzoic acid<smiles>O=C(O)c1ccc(O)c(O)c1</smiles>

protocatechuic acid<smiles>COc1cc(C(=O)O)ccc1O</smiles>

vanillic acid syringic acid

Cinnamic acid derivatives<smiles>O=C(O)/C=C/c1ccccc1O</smiles>

o-coumaric acid<smiles>O=C(O)/C=C/c1cccc(O)c1</smiles>

m-coumaric acid<smiles>O=C(O)/C=C/c1ccc(O)cc1</smiles>

p-coumaric acid<smiles>O=C(O)/C=C/c1ccc(O)c(O)c1</smiles>

caffeic acid

Flavonols<smiles>O=c1c(O)c(-c2ccc(O)c(O)c2)oc2cc(O)cc(O)c12</smiles>

quercetin<smiles>COc1c(-c2ccc(O)c(O)c2)oc2cc(O)cc(O)c2c1=O</smiles>

rutin

Cyclic voltammograms of all three monohydroxybenzoic acid isomers (Figure 2) present only one well defined anodic peak and no reverse peak is observed. As can be seen in insert A of Figure 2, the 
anodic peak current increased in proportion to the square root of scan rate, pointing to a diffusion controlled response.

Figure 2. Overlapped cyclic voltammograms of $1 \mathrm{mM} m$-hydroxybenzoic acid, as typical monohydroxybenzoic acid, obtained at scan rates of 25, 50, 100, 200, 300, 400 and 500 $\mathrm{mVs}^{-1}$. Insert A shows the linear plot of anodic peak currents versus square root of scan rate.
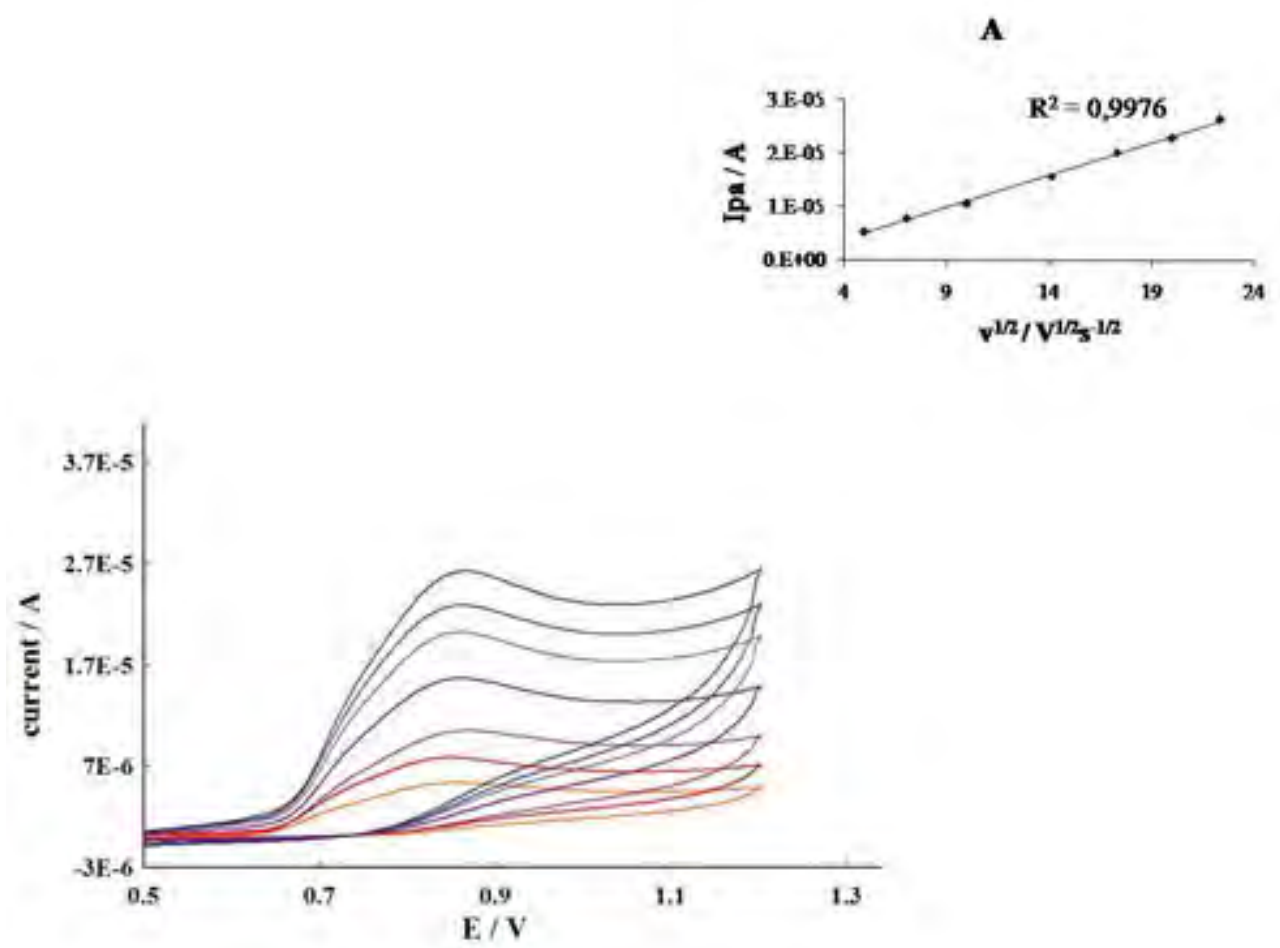

The absence of a cathodic peak in the reverse scan indicates an oxidation process that was followed by a chemical reaction which rapidly removed generated product. Slight changes of current function $i_{p} / v^{1 / 2}$ with increase scan rate also point out to an EC mechanism [6]. Although it is generally believed that the initial stage in oxidation of phenols leads to formation of a phenoxonium ion (Figure 3) there are reports that the principal product also may be a phenoxy radical $[7,8]$. These products may undergo further chemical reactions such as coupling, proton loss or nucleophilic attack [7-9].

Though a number of possible phenoxonium ion intermediates may be formed, the structure in which a positive charge is on a carbon atom that already suffers an electron deficiency due to the electron-withdrawing effect of a $\mathrm{COOH}$ group is unlikely. Therefore, $p$ - and $o$-hydroxybenzoic acids are wave shifted toward positive potentials, compared to the corresponding meta isomer, which has no positive charge on the carbon atom attached to the $\mathrm{COOH}$ group. Hence, the meta isomer is the most easy to oxidize of all three derivatives. In the case of $o$-hydroxybenzoic acid steric effects may also contribute to the shift of potential.

Introduction of a second hydroxyl group in the benzene ring lead to considerable reduction of Epa values (Table 1). Cyclic voltammogram of protocatechuic acid show single anodic and cathodic peaks but the difference between anodic and cathodic peak potential value indicates an irreversible electrode process (Figure 4). The peak current ratio $I_{p d} / I_{p a}$ increases until reaches a fixed value and current 
function $I_{p a} / v^{1 / 2}$ gradually decrease with increasing scan rate. Such a behavior is adopted as indicative of ECE mechanism [10].

Table 1. First oxidation potentials and antioxidant activities of phenol compounds.

\begin{tabular}{lcc}
\hline \hline \multicolumn{1}{c}{ Phenolics } & Epa (V) ${ }^{\mathbf{a}}$ & $\begin{array}{c}\text { Lipid peroxidation } \\
\text { (percent inhibition) }^{\mathbf{b}}\end{array}$ \\
\hline salicylic acid & 0.94 & $-12.1 \pm 1.8$ \\
$m$-hydroxy-benzoic acid & 0.83 & $-10.1 \pm 3.0$ \\
$p$-hydroxy-benzoic acid & 0.87 & $-11.4 \pm 2.0$ \\
protocatechuic acid & 0.41 & $+15.5 \pm 0.3$ \\
vanillic acid & 0.73 & $-12.5 \pm 1.1$ \\
syringic acid & 0.49 & $-5.4 \pm 1.1$ \\
-coumaric acid & 0.75 & $-13.0 \pm 1.0$ \\
$m$-coumaric acid & 0.78 & $-10.6 \pm 1.1$ \\
p-coumaric acid & 0.67 & $-23.3 \pm 3.1$ \\
caffeic acid & 0.45 & $+11.2 \pm 2.2$ \\
quercetin & 0.10 & $+67.8 \pm 2.0$ \\
rutin & 0.23 & $+10.0 \pm 3.6$ \\
\hline a & first oxidation peak potential at scan rate of 100mVs ${ }^{-1}$ & \\
b & values with the sign - represent percent of prooxidant activity. Data are the means at least three \\
experiments. &
\end{tabular}

Figure 3. Electrochemical oxidation of phenolic compounds.

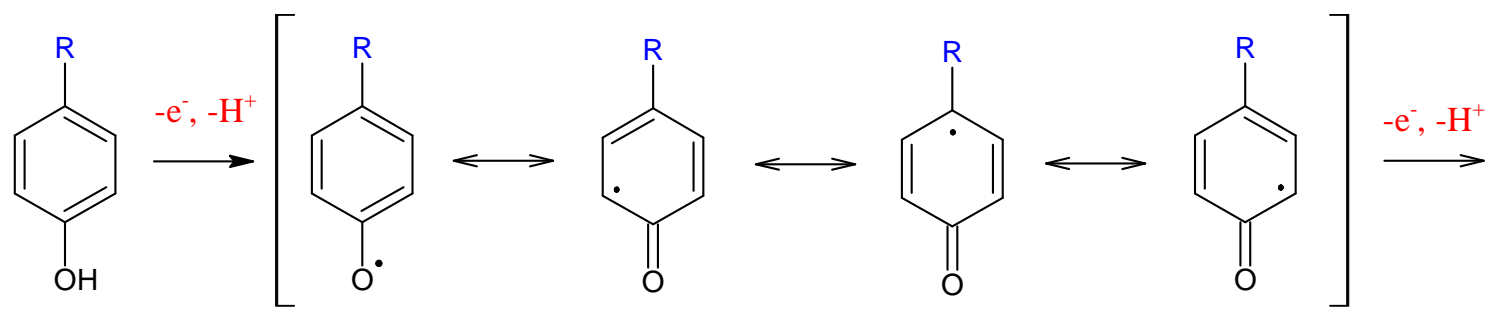

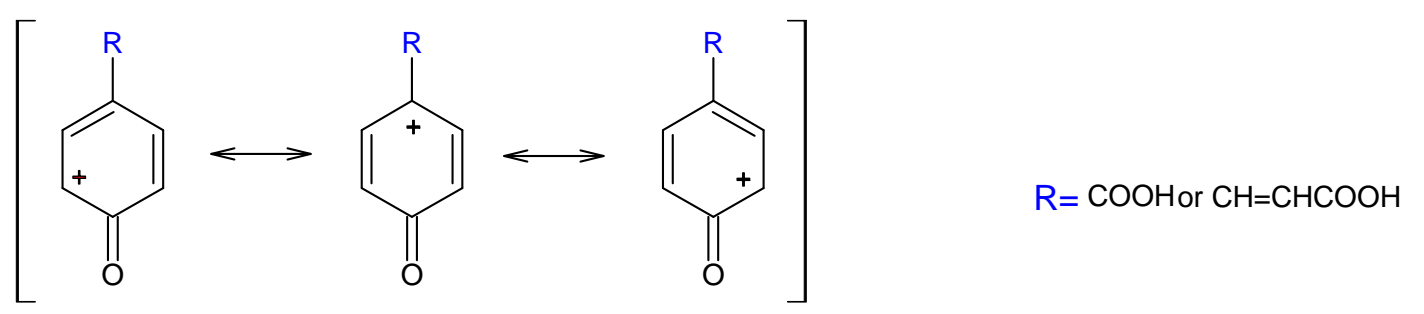


It was observed that oxidation of phenolic compounds with the hydroxy group in the ortho position leads to the formation of quinone and to a lowering of the electrochemical potential $[11,12]$.

Figure 4. Overlapped cyclic voltammograms of $1 \mathrm{mM}$ protocatechuic acid obtained at scan rates of 25, 50, 100, 200, 300, 400 and $500 \mathrm{mVs}^{-1}$. Insert A shows the linear plot of anodic peak currents versus square root of scan rate.
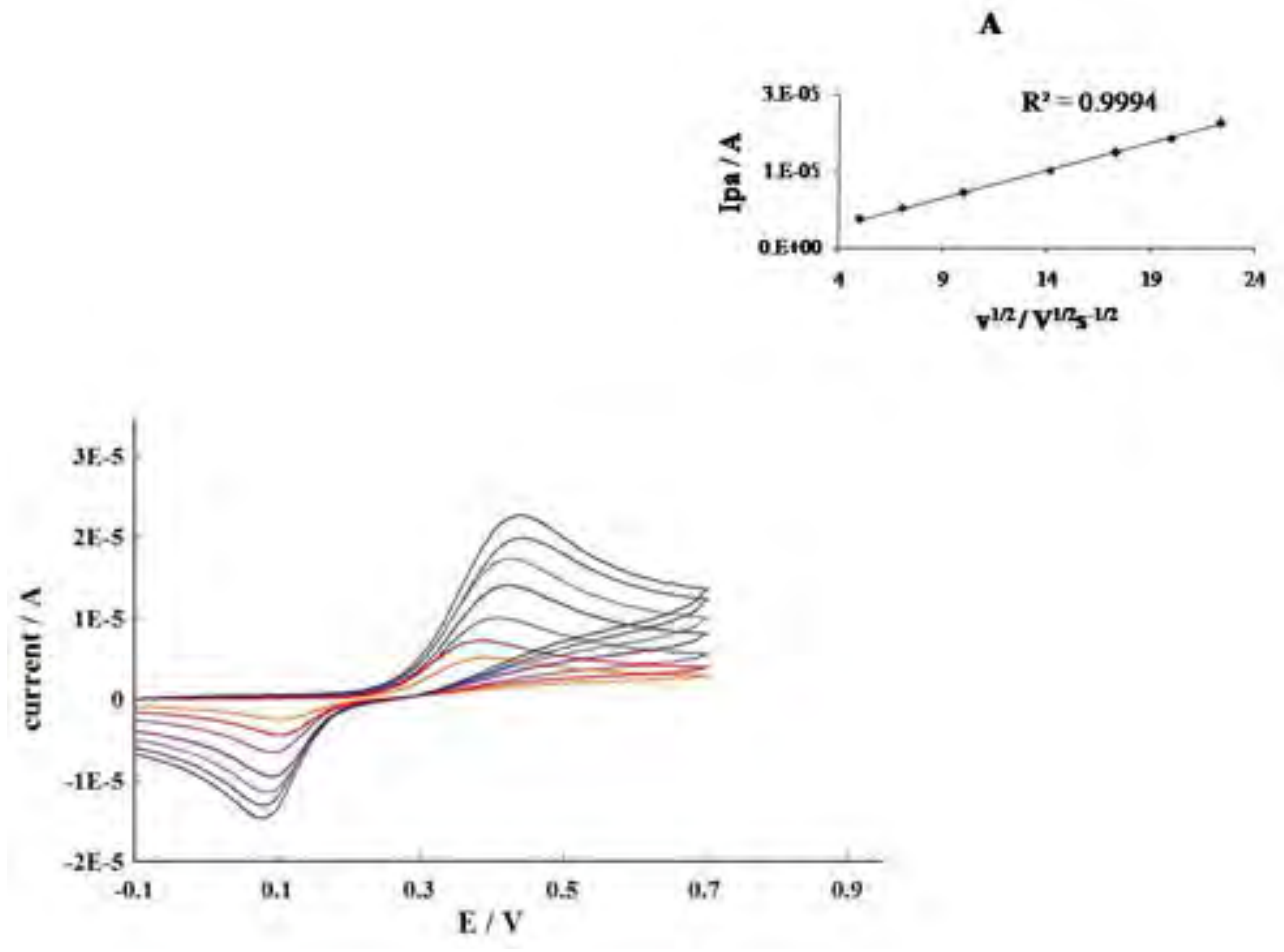

Introduction of a methoxy group instead of a hydroxyl in the position meta to the $\mathrm{COOH}$ shifts the Epa toward more positive value (Table 1). The peak potential was lower than the electrochemical potentials of monohydroxybenzoic acids, probably due to conjugative electron donation of the $\mathrm{OCH}_{3}$ group and stabilization of the intermediate cation. The cyclic voltammogram of vanillic acid (Figure 5) shows only one anodic peak and no reverse cathodic peak. From the linear increase of the anodic peak current with the square root of the scan rate it is evident that the oxidation process was diffusion controlled. The current function changes only slightly with increasing scan rate suggesting an EC mechanism [6].

Similar results are noted in the voltammogram of syringic acid, except in this case introduction of another methoxy group lead to a reduction of the Epa value in comparison to that of vanillic acid (Figure 6). 
Figure 5. Overlapped cyclic voltammograms of $1 \mathrm{mM}$ vanillic acid obtained at scan rates of 25, 50, 100, 200, 300, 400 and $500 \mathrm{mVs}^{-1}$. Insert A shows the linear plot of anodic peak currents versus square root of scan rate.

$\mathbf{A}$
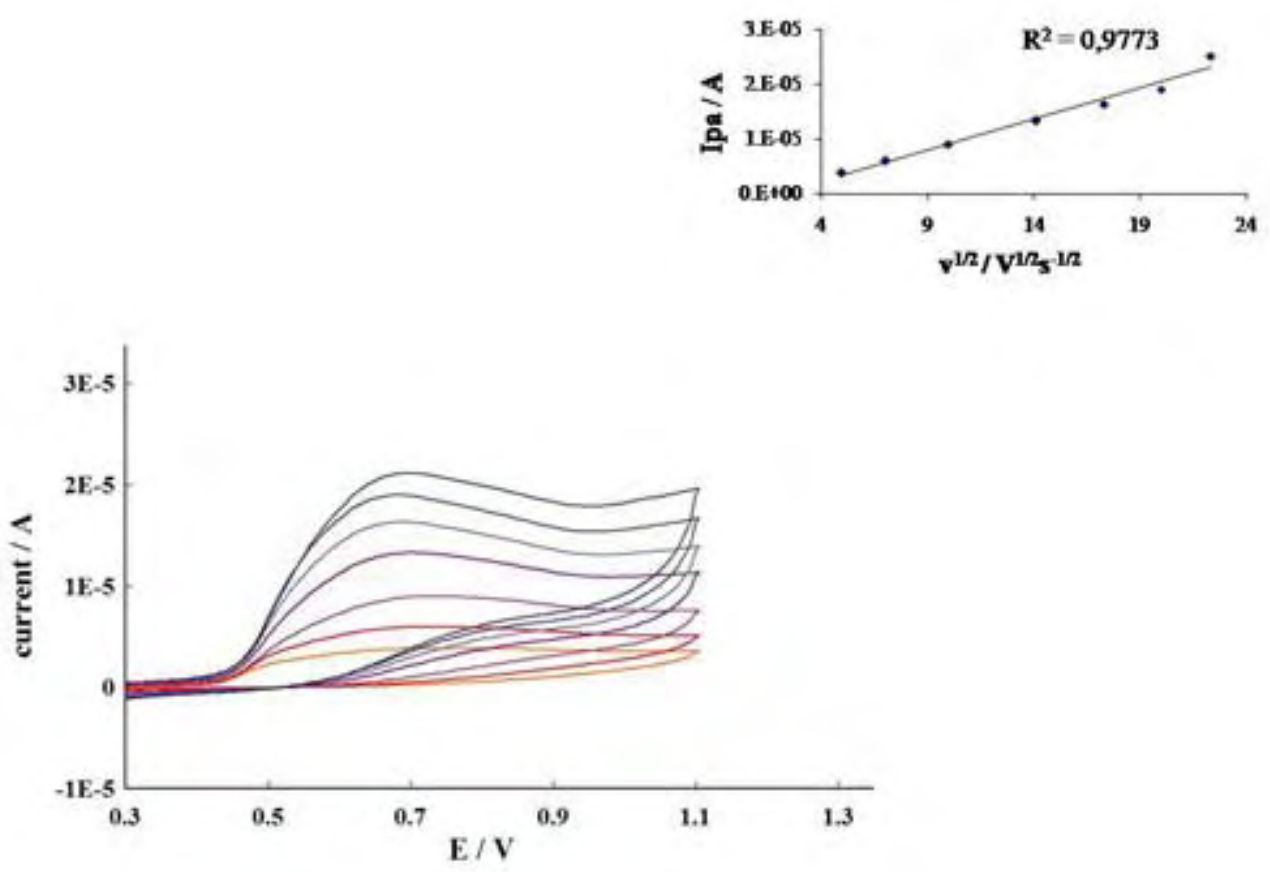

Figure 6. Overlapped cyclic voltammograms of $1 \mathrm{mM}$ syringic acid obtained at scan rates of $25,50,100,200,300,400$ and $500 \mathrm{mVs}^{-1}$. Insert A shows the linear plot of anodic peak currents versus square root of scan rate.
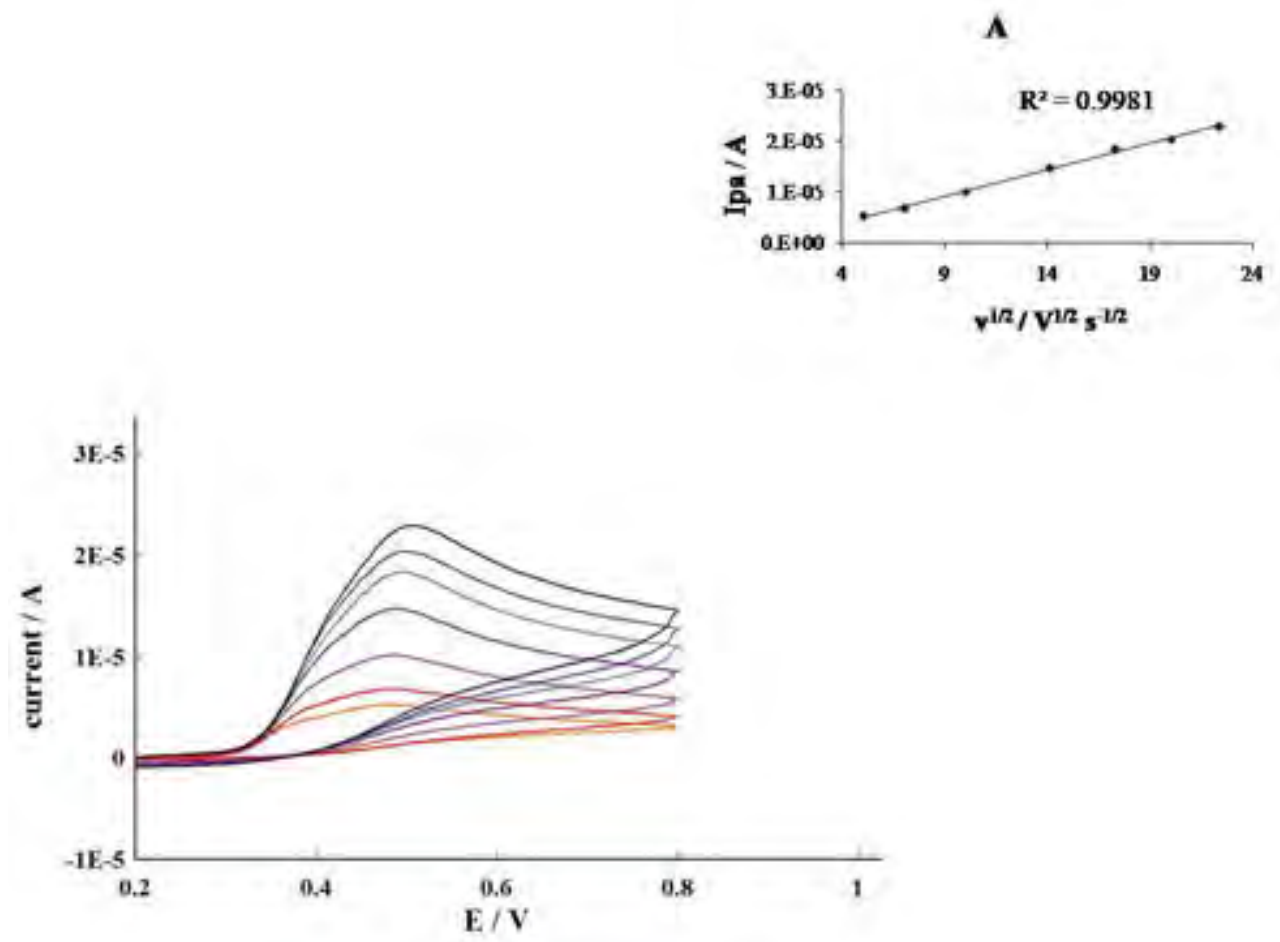
Cinnamic acid derivates also undergo an irreversible oxidation (Figure 7). However, comparison of the anodic peak potential value reveals that in these case para isomer is most easily to oxidize due to hiperconjugation to the aromatic ring of $\mathrm{CH}=\mathrm{CHCOOH}$ group. Linear plots of peak current $I_{p a}$ as function of $v^{1 / 2}$ point out that oxidation processes are diffusion controlled. The current function was slightly changed with scan rate indicating EC mechanism [6].

Figure 7. Overlapped cyclic voltammograms of $1 \mathrm{mM}$-coumaric acid, as a typical mono-hydroxycinnamic acid, obtained at scan rates of 25, 50, 100, 200, 400 and 500 $\mathrm{mVs}^{-1}$. Insert A shows linear plot of anodic peak currents versus square root of scan rate.

$\mathbf{A}$
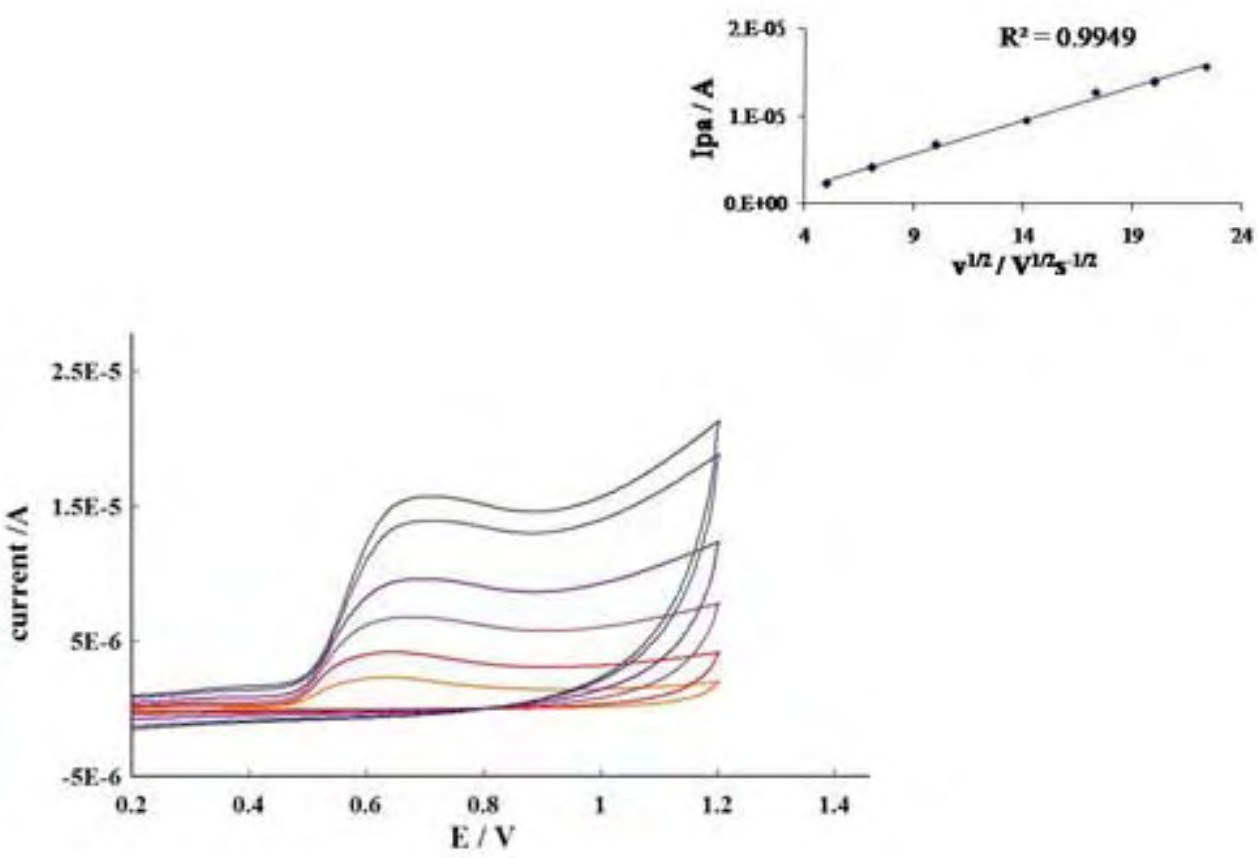

The anodic oxidation of caffeic acid show irreversible anodic and cathodic waves (Figure 8). The ratio of the cathodic to anodic peak heights increases gradually until it reaches a fixed value and the current function $I_{p a} / v^{1 / 2}$ declines with the scan rate, suggesting an ECE mechanism [10]. From Table 1 it is evident that introduction of a hydroxyl group in $p$-coumaric acid leads to a significant reduction in the Epa value. It is generally accepted that oxidation of caffeic acid leads to o-quinones via semiquinone forms [9,11].

Hotta et al. [9] have studied the electrochemical oxidation mechanism of caffeic acid. According to them, digital simulation analysis showed that the EqCiEqCi mechanism best fitted the experimental results. They indicated that a semiquinone radical and quinone may undergo a further dimerization, although the oxidation processes are not fully understood.

The cyclic voltammograms of quercetin and rutin are shown in Figures 9 and 10. Quercetin at a scan rate of $100 \mathrm{mV} \mathrm{s}^{-1}$ presented three oxidation peaks: the first at $0.10 \mathrm{~V}$, a second one at $c a .0 .47 \mathrm{~V}$ and a third at $c a .0 .85 \mathrm{~V}$. On the negative scan a reduction peak appeared at about $0.08 \mathrm{~V}$. On the other hand, the voltammogram of rutin shows only two oxidation peaks at $0.23 \mathrm{~V}$ and $c a .0 .95 \mathrm{~V}$ and one reduction peak at about $0.21 \mathrm{~V}$. These results are in agreement with relevant literature $[13,14]$. Both 
quercetin and rutin show electrochemical behavior which point out to the diffusion controlled electrode process involving chemical reaction subsequent to the electron transfer.

Figure 8. Overlapped cyclic voltammograms of $1 \mathrm{mM}$ caffeic acid obtained at scan rates of $25,50,100,200,300,400$ and $500 \mathrm{mVs}^{-1}$. Insert A shows the linear plot of anodic peak currents versus square root of scan rate.
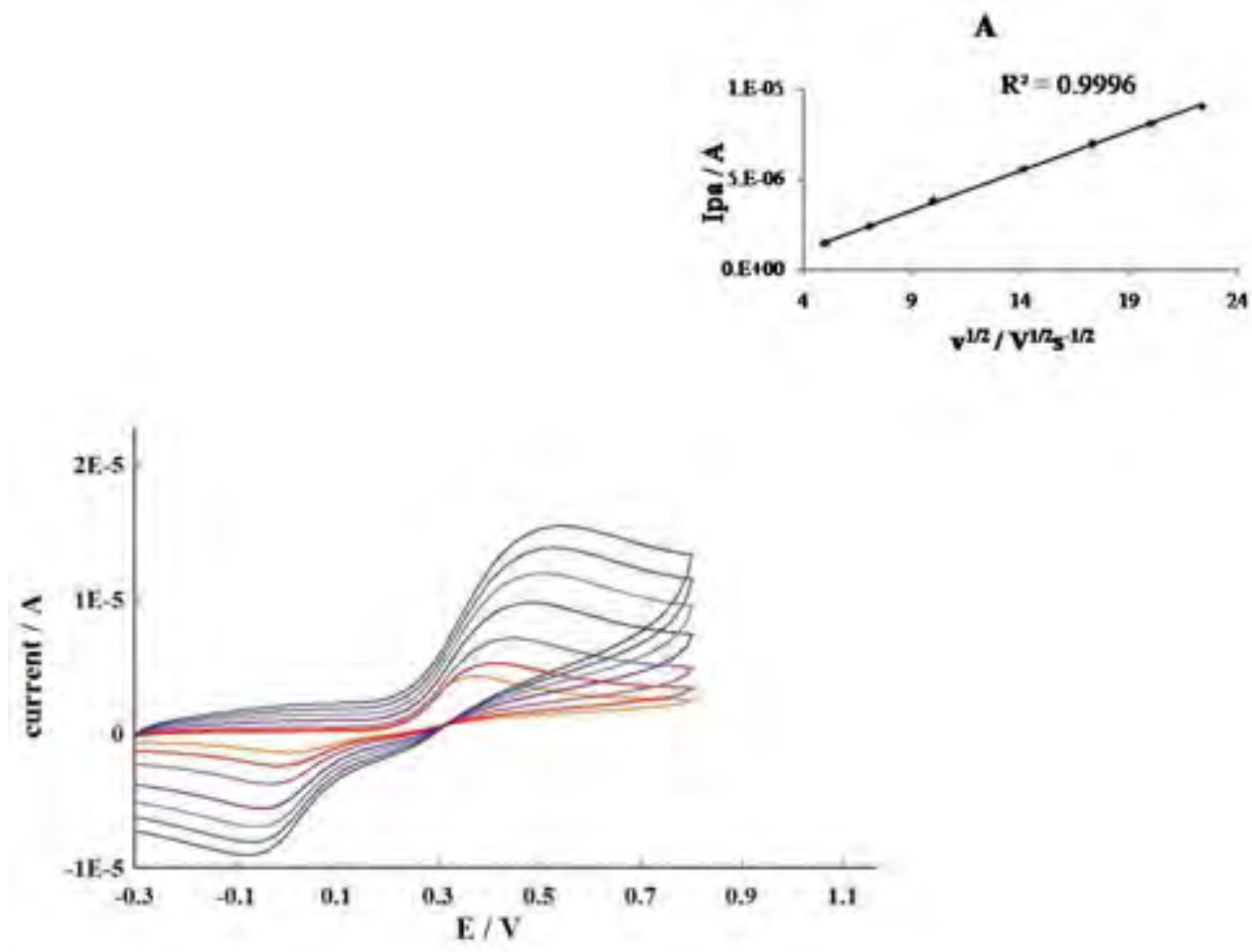

Figure 9. Overlapped cyclic voltammograms of $1 \mathrm{mM}$ quercetin obtained at scan rates of 25, 50, 100, 200, 300, 400 and $500 \mathrm{mVs}^{-1}$. Insert A shows the linear plot of anodic peak current versus square root of scan rate.
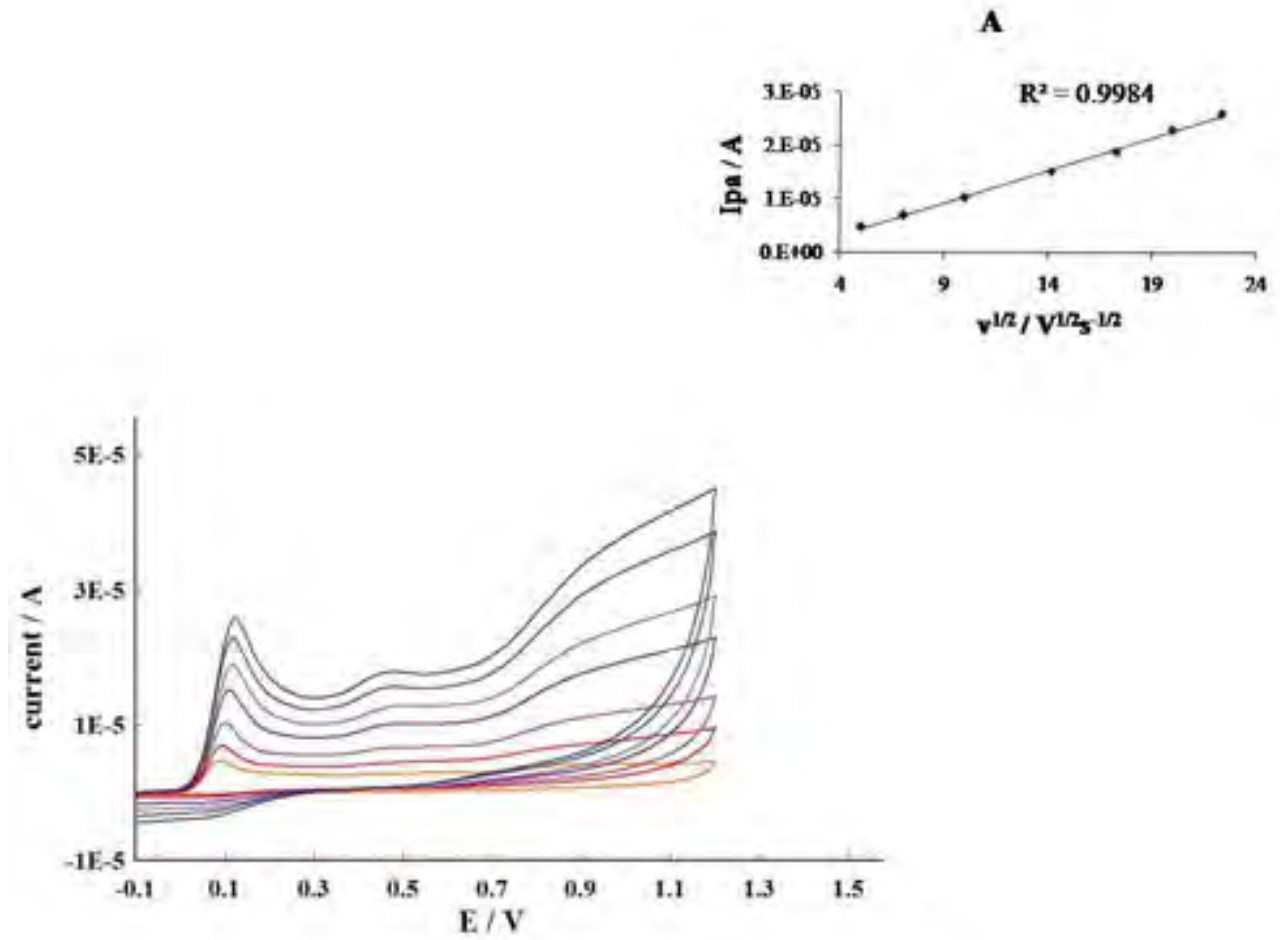
Although the oxidation pathways of flavonols, and quercetin in particular, were extensively investigated, the electrochemical processes are not completely understood. The first voltammetric peak is unequivocally attributed to the oxidation of the 3',4'-dihydroxy substituent on the B-ring. On the other hand, the explanation for the second and third is not so uniform, but most investigators agree that the peaks at $0.47 \mathrm{~V}$ and $0.85 \mathrm{~V}(0.95 \mathrm{~V}$ in the case of rutin) correspond to the oxidation of the $\mathrm{C}-3$ hydroxyl group and to the resorcinol moiety, respectively [13-16]. Those conclusions were supported by the lack of second peak in the rutin voltammogram since rutin has the C-3 hydroxyl group conjugated to a rutinose.

Figure 10. Overlapped cyclic voltammograms of $1 \mathrm{mM}$ rutin obtained at scan rates of 25, $50,100,200,300,400$ and $500 \mathrm{mVs}^{-1}$. Insert A shows linear plot of anodic peak currents versus square root of scan rate.

$\mathbf{A}$
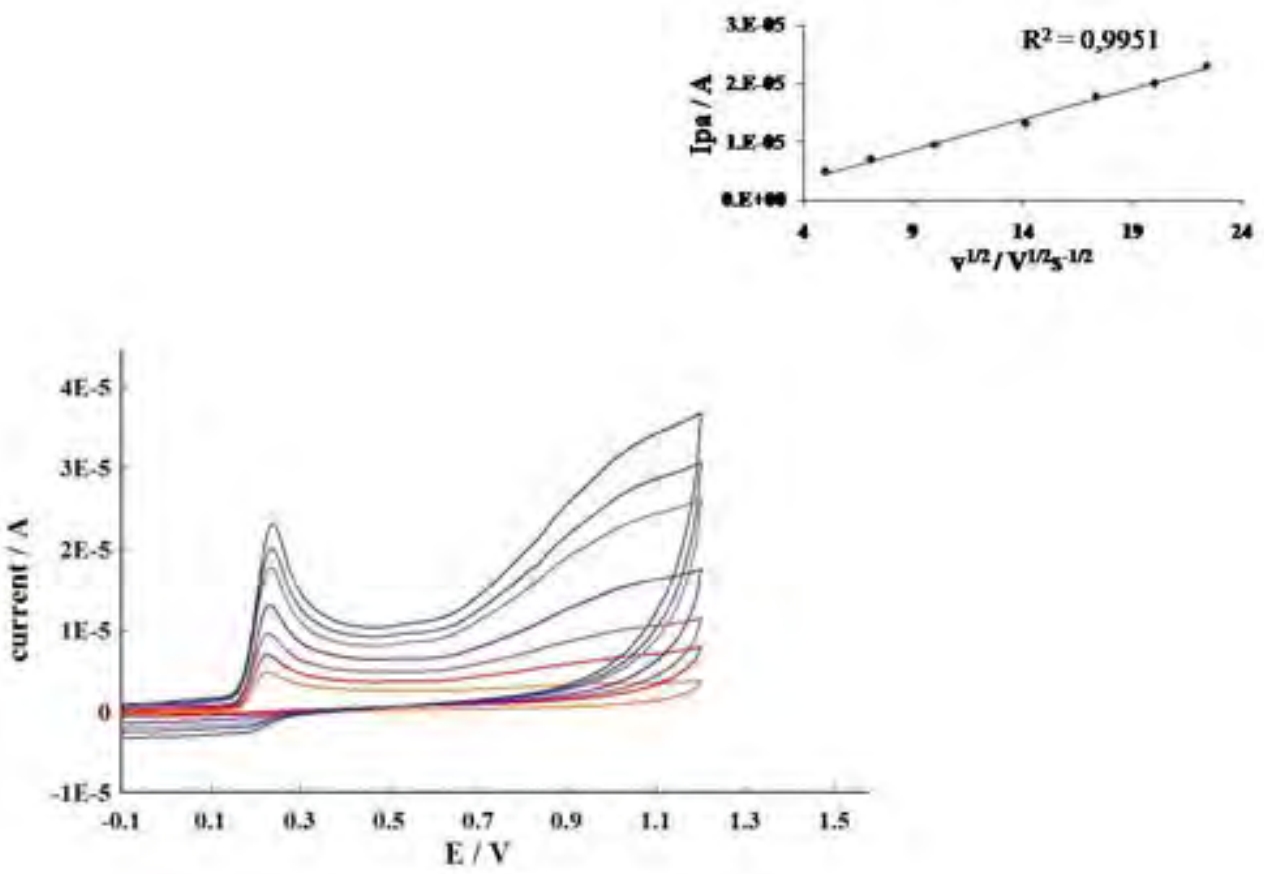

The ability of phenolic compounds to promote or inhibit oxidative damage in lipids was assessed using linolenic acid as a model system. Peroxidation was initiated by addition of $\mathrm{FeSO}_{4}$-ascorbic acid mixture. It is well known that transition metals like iron or copper may generate highly reactive hydroxyl or alkoxyl radicals (Fenton reaction) [17] which can be detected by their ability to degrade the linolenic acid and to form malonaldehyde. The aldehyde produced this way reacts with thiobarbituric acid and generates a pink chromogen. The results of the antioxidative assay are shown in Table 1.

Phenols can act as antioxidants by radical scavenging, in which they break the free radical chain reaction through hydrogen atom donation [5]. The resulting phenoxy radical can be reduced to its parent compound by enzymatic or nonenzymatic reactions [18]. Another possible antioxidant mechanism is via metal chelation and restriction of the accessibility of the metal ion for participation in Fenton-type reactions [19]. 
However, phenolic can exert prooxidant effects by autoxidation, in which the initial step leads to semiquinone and superoxide $\left(\mathrm{O}_{2}{ }^{-}\right)$radical formation [20]. These radicals are very reactive and may damage major macromolecules such as proteins or DNA [18]. Moreover, both radicals will accelerate autoxidation, generating $\mathrm{H}_{2} \mathrm{O}_{2}$ in the process $[18,20]$. It was reported that presence of transition metals or $\mathrm{H}_{2} \mathrm{O}_{2}$ can reduce the antioxidant capacity of phenolics [18-22]. The increase in prooxidative activity of phenolics in the presence of $\mathrm{Fe}(\mathrm{III})$ or $\mathrm{Cu}(\mathrm{II})$ was primarily associated with their ability to reduce metal ion. Subsequently $\mathrm{Fe}(\mathrm{III})$ and $\mathrm{Cu}(\mathrm{II})$ can be reoxidized in Fenton-type reactions leading to the production of ${ }^{\circ} \mathrm{OH}$ and other reactive oxygen species. Also, the antioxidant/prooxidant activity of phenolics were determined by many factors like the concentration and nature of transition metal ion(s) present, the concentration of phenolics and $\mathrm{pH}[23,24]$.

It is evident that of the twelve investigated compounds only four show antioxidant activity under the experimental condition used, whereas the others were prooxidants. All monosubstituted phenols exhibited similar prooxidation activity. The only exception was $p$-coumaric acid which surprisingly strong promoted lipid degradation. It has been previously observed that monohydroxylated compounds have a very poor radical scavenging activity [25, 26]. Fukumoto et al. [27] found that many compounds, including benzoic and cinnamic acid derivatives, can behave like prooxidants depending on their concentration. There are also reports that exogenous treatment of plants with salicylic acid enhanced lipid peroxidation and oxidative damage to proteins [28]. However, caffeic and protocatechuic acids act as antioxidants. It has been observed that presence of two hydroxyl groups in ortho position increase antioxidant activity due to additional resonance stabilization and $o$-quinone formation [25, 26, 29]. Nevertheless, the methylation of the 3-hydroxyl group in protocatechuic acid to form vanillic acid caused a significant reduction of the radical scavenging capacity. Introduction of another methoxy group in the 5-position to form syringic acid slightly decreased the prooxidant activity.

Although both quercetin and rutin inhibited malonaldehyde formation, the antioxidant response of the rutin was weak. Bors et al. [30] proposed three structural features of flavonoids that determine their radical scavenging capabilities: the 3'4'dihydroxy substitution in the B ring, which provides good electron delocalization and stabilization of the phenoxy radical and coexistence of the 2,3-double bond in conjugation with the 4-keto group and the 3-hydroxy group on the $\mathrm{C}$ ring, which increases the delocalization of electron across the flavonoid nucleus. Quercetin, which satisfies all these requirements, has high antioxidant activity. However, glycosylation of the 3-hydroxyl group to form rutin resulted in the loss of scavenging capabilities.

Cyclic voltammetry has been applied to characterize the reducing ability of natural phenolics [13, 31, 32] and good correlations have been observed between redox potentials and antioxidant properties $[33,34]$. It is found that compounds with strong scavenging capabilities are oxidized at relatively low potentials [12, 34]. However, the most powerful reducing agents are phenolics with low reducing potential and they can, by autoxidation, exert prooxidant activity [35]. Thus, the balance between antioxidative and prooxidative effects is very delicate.

The phenolic compounds that we examined here show a connection between Epa and the ability to inhibit or promote lipid peroxidation. Of all studied substances, only quercetin showed high radical scavenging activity and consequently its anodic potential was low. The phenolics that have oxidation potentials between $0.2 \mathrm{~V}$ and $0.45 \mathrm{~V}$ are less active, but still inhibit lipid peroxidation. The third group 
contains compounds that have anodic potentials higher than $0.45 \mathrm{~V}$. The phenols in this group promoted lipid peroxidation. Using flow-through column electrolysis Yang et al. [31] reported that glycosylation of the 3-hydroxyl group of quercetin lead to an increased oxidation potential and decrease of antioxidant activity. A similar relationship was observed by Firuzi et al. [34]], using CV for oxidation potential measurement and ferric reducing antioxidant power for evaluation of the antioxidant activity. The increase in antioxidant activity and decrease of Epa with an increased number on hydroxyl groups on the aromatic ring was also observed. Sousa et al. [12] found that caffeic acid had a lower Epa value and higher free radical scavenging activity than $p$-coumaric acid and that methoxylation of the phenolic groups increased the Epa value and reduced antioxidant activity. However, it was observed that many polyphenols like flavonoids and caffeic acid, have ability to reduce transition metal ion and consequently to act as prooxidants [18, 21, 25, 36]. Thus, the relatively low antioxidant activity of phenols in the second group, especially rutin, may be partially due to the lowering effect of autooxidation in the presence of Fe(III) ion. The compounds such as p-coumaric acid with lower Epa than the rest of the monosubstituted acids, yet strong prooxidation activity, suggest that properties beside oxidation potential must be considered when antioxidation and prooxidation activity are evaluated.

\section{Conclusions}

From these studies, it was concluded that cyclic voltammetry can be used to characterize the reducing ability and electrochemical behavior of phenolic antioxidants. The measured oxidation potential was closely related to the structures of the investigated compounds. The phenolic structure also influences antioxidant activity. The compounds with two or more electron donating groups have lower anodic peak potentials and higher antioxidant abilities then monosubstituted phenols, although $\mathrm{OH}$ groups have stronger effects then $\mathrm{OCH}_{3}$ ones. Generally there is relationship between antioxidative and prooxidative activities and oxidation potentials. All compounds with low anodic potential $(<0.45 \mathrm{~V})$ inhibit lipid peroxidation, whereas compound with high Epa $(>0.45 \mathrm{~V})$ act as prooxidants.

\section{Experimental}

\section{General}

Salicylic acid, $m$-hydroxybenzoic acid, $p$-hydroxybenzoic acid, protocatechuic acid, vanillic acid, syringic acid, $o$-coumaric acid, $m$-coumaric acid, $p$-coumaric acid, caffeic acid, quercetin and rutin were purchased from Sigma-Aldrich.

\section{Cyclic Voltammetry}

Voltammetric measurements were performed on a Metrohm VA 797 Computrace potentiostat. The working electrode was glassy carbon, a platinum wire was used as counter electrode and $\mathrm{Ag} / \mathrm{AgCl}$ was employed as the reference. Prior to each electrochemical measurement the working electrode was cleaned by polishing with alumina powder on polishing cloth. The standard solution were prepared by 
dissolving the phenolics to the concentration of $1 \mathrm{mM}$ in solvent containing $5 \%(\mathrm{v} / \mathrm{v})$ ethanol and phosphate buffer $\left(\mathrm{pH}\right.$ 7.0) with $0.1 \mathrm{M} \mathrm{KNO}_{3}$ as supporting electrolyte. Quercetin and rutin were dissolved in methanol-phosphate buffer ( $\mathrm{pH}$ 7.0) with $0.1 \mathrm{M} \mathrm{KNO}_{3}(1: 1, \mathrm{v} / \mathrm{v})$ due to their low solubility in water. The solution was purged with nitrogen for $2 \mathrm{~min}$. The cyclic voltammograms were recorded at a scan rates of $25 \mathrm{mVs}^{-1}, 50 \mathrm{mVs}^{-1}, 100 \mathrm{mVs}^{-1}, 200 \mathrm{mVs}^{-1}, 300 \mathrm{mVs}^{-1}, 400 \mathrm{mVs}^{-1}$ and 500 $\mathrm{mVs}^{-1}$.

\section{Lipid peroxidation}

The antioxidant activity was measured according to the slightly modified method of Matkowski et al. [37]. The reaction mixture $(1.25 \mathrm{~mL})$ containing tested compound $(5 \mu \mathrm{mol})$, phosphate buffer $(\mathrm{pH}$ 7.0, $300 \mu \mathrm{L}), 4 \mathrm{mM} \mathrm{FeSO}_{4}(100 \mu \mathrm{L})$ and $5 \mathrm{mM}$ ascorbic acid $(100 \mu \mathrm{L})$ were incubated for $60 \mathrm{~min}$ at 37 ${ }^{\circ} \mathrm{C}$. the reaction was terminated by adding $10 \%$ ice cold trichloroacetic acid $(2 \mathrm{~mL})$ followed by addition of $1 \%$ thiobarbituric acid $(1 \mathrm{~mL})$. The reaction mixture was heated in the water bath at $95{ }^{\circ} \mathrm{C}$ for another $60 \mathrm{~min}$. After centrifugation at $3000 \mathrm{~g}$ for $15 \mathrm{~min}$, absorbance was read at $532 \mathrm{~nm}$ and percentage of peroxidation inhibition was calculated according to Choi et al. [38].

\section{References}

1. Visioli, F.; Galli, C. Olive oil phenols and their potential effects on human health. J. Agric. Food Chem. 1998, 46, 4292-4296.

2. Spanos, A.G.; Wrolstad, E.R. Phenolics of apple, pear, and white grape juices and their changes with processing and storage-a review. J. Agric. Food Chem. 1992, 40, 1478-1487.

3. Ingram, D.; Sanders, K.; Kolybaba, M.; Lopez, D. Case-control study of phytoestrogens and breast cancer. Lancet 1997, 9083, 990-994.

4. Vinson, A.J.; Hao, Y.; Su, X.; Zubik, L. Phenol antioxidant quantity and quality in foods: vegetables. J. Agric. Food Chem. 1993, 46, 3630-3634.

5. Sawa, T.; Nakao, M.; Akaike, T.; Ono, K.; Maeda, H. Alkylperoxyl radical-scavenging activity of various flavonoids and other phenolic compounds: implications for the anti-tumor-promoter effect of vegetables. J. Agric. Food Chem. 1999, 47, 397-402.

6. Bard, A.J.; Faylkner, L.R. Electrochemical methods, fundamentals and applications, Second Ed.; Wiley: New York, 2001; pp. 496-505.

7. Ferreira, M.; Varela, H.; Torresi, R.M.; Tremiliosi-Filho, G. Electrode passivation caused by polymerization of different phenolic compounds. Electrochim. Acta 2006, 52, 434-442.

8. Lund, H.; Hammerich, O. Organic electrochemistry, Fourth Ed.; Marcel Dekker: New York, 2001; pp. 590-611.

9. Hotta, H.; Ueda, M.; Nagano, S.; Tsvjino, Y.; Koyama, J. Mechanistic study of the oxidation of caffeic acid by digital simulation of cyclic voltammograms. Anal. Biochem. 2002, 303, 66-72.

10. Nicholson, S.R.; Shain, I. Theory of stationary electrode polarography for a chemical reaction coupled between two charge transfers. Anal. Chem. 1965, 37, 178-190.

11. Trabelsi, S.K.; Tahar, N.B.; Abdelhedi, R. Electrochemical behavior of caffeic acid. Electrochim. Acta 2004, 49,1647-1654. 
12. Sousa, R.W.; da Rocha, C.; Cardoso,C.L.; Silva, S.D.H.; Zanoni, B.M.V. Determination of the relative contribution of phenolic antioxidants in orange juce by voltammetric methods. J. Food Com. Anal. 2004, 17, 619-633.

13. Born, M.; Carrupt, P.A.; Zini, R.; Bree, F.; Tillement, J.P.; Hostettmann, K.; Testa, B. Electrochemical behaviour and antioxidant activity of some natural polyphenols. Helv. Chim. Acta 1996, 79, 1147-1158.

14. Hendrickson, P.H.; Kaufman, D.A.; Lunte, E.C. Electrochemistry of catehol-containing flavonoids. J. Pharm. Biomed. Anal. 1994, 12, 325-334.

15. Ghica, M.E.; Brett, A.M.O. Electrochemical oxidation of rutin. Electroanalysis 2005, 17, 313318.

16. Brett, A.M.O.; Ghica, M.E. Electrochemical oxidation of quercetin. Electroanalysis 2003, 15, 1745-1750.

17. Halliwell, B.; Gutteridge, J.M.C. Oxygen toxicity, oxygen radicals, transition metals and disease. Biochem. J. 1984, 219, 1-14.

18. Sakihama, Y.; Cohen, M.F.; Grace, S.C.; Yamasaki, H. Plant phenolic antioxidant and prooxidant activities: phenolics-induced oxidative damage mediated by metals in plants. Toxicology 2002, 177, 67-80.

19. Cheng, Z.; Li, Y.; Chang, W. Kinetic deoxyribose degradation assay and its application in assessing the antioxidant activities of phenolic compounds in a Fenton- type reaction system. Anal. Chim. Acta 2003, 478, 129-137.

20. Mochizuki, M.; Yamazaki, S.; Kano, K.; Ikeda, T. Kinetic analysis and mechanistic aspects of autoxidation of catehins. Biochim. Biophys. Acta 2002, 1569, 35-44.

21. Labieniec, M.; Gabryelak, T. Study of interactions between phenolic compounds and $\mathrm{H}_{2} \mathrm{O}_{2}$ or $\mathrm{Cu}$ (II) ions in B14 Chinese hamster cells. Cell Boil. Intr. 2006, 30, 761-768.

22. Labieniec, M.; Gabryelak, T. Antioxidative and oxidative changes in the digestive gland cells of freshwater mussels Unio tumidus caused by selected phenolic compounds in the presence of $\mathrm{H}_{2} \mathrm{O}_{2}$ or $\mathrm{Cu}^{2+}$ ions. Toxicol. In Vitro 21, 146-156.

23. Rodtjer,A.; Skibsted, L.H.; Andersen, M.L. Antioxidative and prooxidative effects of extracts made from cherry liqueur pomace. Food Chem. 2006, 99, 6-14.

24. Kumamoto, M.; Sonda, T.; Nagayama, K.; Tabata, M. Effects of $\mathrm{pH}$ and metal ions on antioxidative activities of catechins. Biosci. Biotechnol. Biochem. 2001, 65,126-132.

25. Briante, R.; Febbraio, F.; Nucci, R. Antioxidant properties of low molecular weight phenols present in the Mediterranean diet. J. Agric. Food Chem. 2003, 51, 6975-6981.

26. Villano, D.; Fernandez-Pachon, M.S.; Troncoso, M.A.; Garcia-Parrilla, M.C. Comparison of antioxidant activity of wine phenolic compounds and metabolites in vitro. Anal. Chim. Acta 2005, 538, 391-398.

27. Fukumoto, L.R.; Mazza, G. Assessing antioxidant and prooxidant activities of phenolic compounds. J. Agric. Food Chem. 2000, 48, 3597-3604.

28. Yu, L.J.; Lan, W.Z.; Quin, W.M.; Xu, H.B. Effects of salicylic acid on fungal elicitor-induced membrane-lipid peroxidation and taxol production in cell suspension cultures of Taxus chinensis. Proc. Biochem. 2001, 37, 477-482. 
29. Natella, F.; Nardini, M.; di Felice M.; Scaccini, C. Benzoic and cinnamic acid derivates as antioxidants: structure-activity relation. J. Agric. Food Chem. 1999, 47, 1453-1459.

30. Bors, W.; Heller, W.; Michel, C.; Saran, M. Flavonoids as antioxidants: determination of radicalscavenging efficiencies. Methods Enzymol. 1990, 186, 343-355.

31. Yang, B.; Kotani, A.; Arai, K.; Kusu, F. Estimation of the antioxidant activities of flavonoids from their oxidation potentials. Anal. Sci. 2001, 17, 599-604.

32. Kilmartin, A.P.; Zou, H.; Waterhouse, L.A. A cyclic voltammetry method suitable for characterizing antioxidant properties of wine and wine phenolics. J. Agric. Food Chem. 2001, 49, 1957-1965.

33. Galato, D.; Ckless, K.; Susin, F.M..; Giacomelli, C.; Robeiro-do-Valle, M.R.; Spinelli, A. Antioxidaant capacity of phenolics and related compounds: correlation among electrochemical, visible spectroscopy methods and structure-antioxidant activity. Redox Report 2001, 6, 243-250.

34. Firuzi, O.; Lacanna, A.; Petrucci, R.; Marrosu, G.; Saso, L. Evaluation of the antioxidant activity of flavonoids by " ferric reducing antioxidant power" assay and cyclic voltammetry. Biochim. Biophys. Acta 2005, 1721, 174-184.

35. Andersen, M. L.; Lauridsen, R.K. Skibsted, L.H. Optimizing the use of phenolic compounds in foods. In Phytochemical Functional Foods; Johnson, I.; Williamson, G., Eds.; Woodhead Publishing Ltd.: Cambridge, 2003; pp. 315-346.

36. Cao, G.; Sofic, E.; Prior, R.L.; Antioxidant and prooxidant behavior of flavonoids: structureactivity relationships. Free Radic. Biol. Med. 1997, 22, 749-760.

37. Matkowski, A; Piotrowska, M. Antioxidant and free radical scavenging activities of some medicinal plants from the Lamiaceae. Fitoterapia 2006, 77, 346-353.

38. Choi, W.C.; Kim, C.S.; Hwang, S.S.; Choi, K.B.; Ahn, J.H.; Lee, Y.M.; Park, H.S.; Kim, K.S. Antioxidant activity and free radical scavenging capacity between Korean medicinal plants and flavonoids by assay-guided comparison. Plant Sci. 2002, 163, 1161-1168.

Sample availability: Contact the authors.

(C) 2007 by MDPI (http://www.mdpi.org). Reproduction is permitted for noncommercial purposes. 